\title{
ASPECTOS MORFO-ANATÔMICOS DO EMBRIÃO DE EUTERPE PRECATORIA MART. DURANTE O PROCESSO GERMINATIVO'
}

\author{
Madalena Otaviano Aguiar ${ }^{2}$ \\ Maria Sílvia de Mendonça ${ }^{3}$
}

Recebido em 20/08/2001. Aceito em 03/12/2001.

\begin{abstract}
RESUMO - (Aspectos morfo-anatômicos do embrião de Euterpe precatoria Mart. durante o processo germinativo). Euterpe precatoria Mart. é uma palmeira amplamente distribuída na bacia Amazônica, em terra firme e em solos de várzea. Dos frutos obtém-se o "vinho do açaî" e do ápice caulinar o palmito, que fazem desta palmeira um importante recurso alimentar. Foi feita a descrição morfo-anatômica do embrião de Euterpe precatoria, durante o processo germinativo, possibilitando o entendimento do mesmo. As observações foram realizadas em microscopio óptico, a partir de cortes histológicos de secções longitudinais e transversais da semente em diversos estádios da germinação. O eixo embrionário é curvo. No início da germinação, forma-se externamente o botão cotiledonar contendo a futura planta. A radícula emerge primeiro, apresentando coifa bem desenvolvida, desenvolvendo-se mais rapidamente que a plúmula. O processo de formação das primeiras folhas é contínuo. À medida que o embrião se desenvolve, a região distal aumenta de tamanho, formando o haustório e ocupando o lugar do endosperma.
\end{abstract}

Palavras-chave - Palmeira, morfo-anatomia, embrião, germinação

\begin{abstract}
Morphological and anatomical studies on germinating seeds of Euterpe precatoria Mart.). Euterpe precatoria is a palm tree widespread in Amazon basin, in terra firme and várzea sites. The fruit is used for the production of Açaí wine, and the sten apex for the production of palm hearts (palmito), which are an important food source. Different stages of germinated açaí seed were studied in longitudinal and transversal sections, under a optical microscope. The embryonic axis is curved. In the early stages of germination, the integument is displaced, forming the cotyledonal bud and the future plant. The radicle emerges first, with a well developed root cap and develops faster than the plumula. The process of formation of the first leaves is continuous. As the embryo is developing, the distal region increases in size, forming the haustorium and occupying the place of the endosperm.
\end{abstract}

Key words - Palm, anatomy, embryo, germination

\footnotetext{
${ }^{1}$ Parte da dissertação de mestrado apresentada ao INPA/UA pela primeira autora

${ }^{2}$ MSc. em Botânica - e-mail: motaviano@fua.br

${ }^{3}$ Prof ${ }^{a}$. Titular - Laboratório de Botânica Agroflorestal - LABAF/FCA/UFAM, e-mail: msilvia@fua.br
} 


\section{Introdução}

Euterpe precatoria Mart. (açaí-solteiro; açaí-do-amazonas) é distribuída por toda a região amazônica (Kanh \& Granville, 1992). É uma das espécies mais difundidas e comuns do gênero e da família, nos Neotrópicos (Henderson, 1995). Calzavara (1972) e Castro (1992) consideram as espécies E. precatoria, E. oleracea e E. edulis como as mais importantes do gênero. Segundo o último autor, isto se deve a amplitude fitogeográfica e a exploração extrativista que sofrem. Euterpe precatoria tem características potenciais para manejo, visto que dela podem ser extraídos o suco do fruto ("vinho de açaî") e o palmito.

A semente constitui um dos principais mecanismos de propagação das palmeiras, principalmente daquelas que não têm perfilhos como Euterpe precatoria. No gênero Euterpe, alguns aspectos morfológicos da germinação foram descritos para a espécie Euterpe edulis por BelinDepoux \& Queiroz (1971). Com relação a espécie Euterpe precatoria, não havia, até o momento, informações na literatura sobre a anatomia da semente durante o processo germinativo.

Considerando a necessidade de tais estudos, em função da propagação da espécie via semente, bem como do entendimento desse mesmo processo, o presente trabalho descreve a morfologia e anatomia do embrião de Euterpe precatoria durante o processo germinativo.

\section{Material e métodos}

As sementes são procedentes das áreas do mini-campus da Universidade do Amazonas, da Rodovia AM-010, Km 09 e 13 (Manaus-Itacoatiara). Para obtenção das sementes e de modo a acelerar o processo germinativo das mesmas, foi procedido o tratamento prévio dos frutos, imergindo-os em água à temperatura de $40^{\circ} \mathrm{C}$ por 20 minutos (Nogueira et al., 1995). Em seguida, retirou-se manualmente a polpa e a parte fibrosa.
Os ensaios para a avaliação morfológica da semente, durante o processo germinativo, foram feitos da seguinte maneira: foram semeadas 70 sementes a $2 \mathrm{~cm}$ de profundidade com o opérculo na posição horizontal e a rafe voltada para baixo, procedimento baseado nas observações de Belin-Depoux \& Queiroz (1971). Como substrato, utilizou-se pó de serragem curtida, mantida sempre úmida, em ambiente de viveiro, com $50 \%$ de luminosidade (Pinheiro, 1986). A cada intervalo de 10 dias, a contar do primeiro dia de semeadura, retirou-se do substrato 10 sementes, perfazendo um total de 70 dias com 7 amostras de 10 sementes cada.

A avaliação anatômica das fases da germinação foi feita através de cortes longitudinais e transversais. Os cortes histológicos foram confeccionados a partir de material fixado em FAA $_{50}$, desidratado progressivamente pelas misturas de etanol-butanol e incluído em parafina a $58^{\circ} \mathrm{C}$ (Kraus \& Arduin, 1997). Posteriormente, os cortes obtidos em micrótomo automático rotativo, foram desparafinizados e corados em Astrablau e Fucsina básica e, finalmente, montados em Bálsamo do Canadá, conforme técnicas usuais. As fotomicrografias foram feitas em fotomicroscópio Axioskop, com câmara MC-80.

\section{Resultados e discussão}

O desenvolvimento do embrião durante o processo germinativo ocorreu num período de 70 dias, cujas fases estão ilustradas nas figuras 1-5.

O pólo radicular, devido a sua posição no embrião, é o primeiro a emergir. Nesta fase, o meristema radicular começa a se organizar; suas células alongam-se e ficam dispostas em fileiras, formando o eixo central da futura raiz (Fig. 6) e o procâmbio aparece originando o protoxilema. A emergência da raiz primária e o seu deslocamento se dão em direção contrária à plúmula (Fig. 7).

Posteriormente, raízes secundárias emergem do periciclo da raiz primária, projetando- 


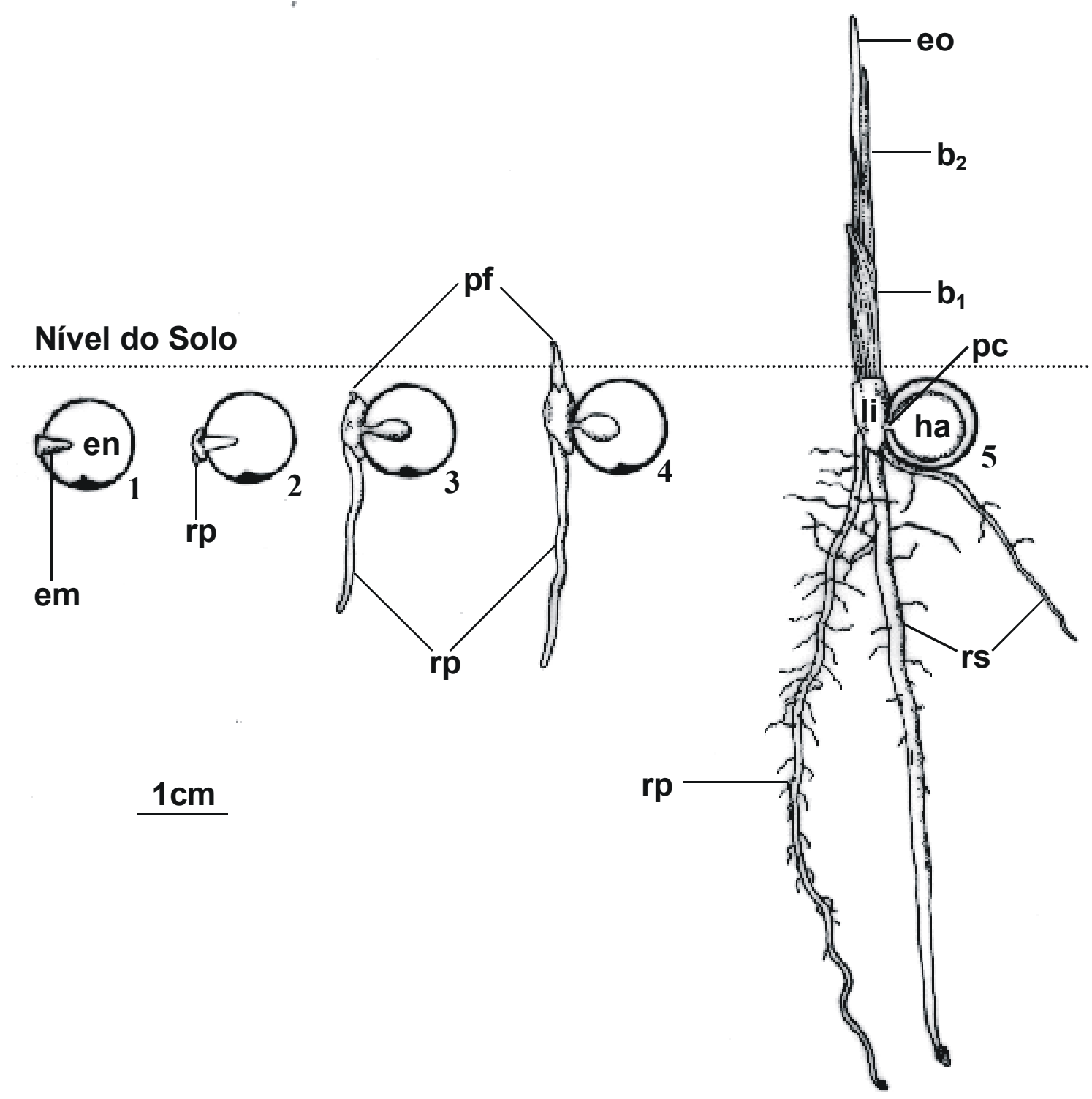

Figura 1-5. Fases do desenvolvimento plantular de Euterpe precatoria Mart. $\mathbf{b}_{1}$, primeira bainha; $\mathbf{b}_{2}$, segunda bainha; ef, eófilo; em, embrião; en, endosperma; ha, haustório; li, lígula; pc, pecíolo cotiledonar; pf, primórdio foliar; rp, raiz primária; rs, raiz secundária.

se em várias direções, apresentando coifa bem desenvolvida (Fig. 8 e 9). Comumente estas raízes secundárias são chamadas de raízes adventícias por alguns autores (Rees, 1960; Corner, 1966; Belin \& Queiroz, 1988, Tomlinson, 1990), entretanto, optou-se por denominá-las de raízes secundárias devido a sua origem no periciclo da raiz primária.
A plúmula tem inicialmente três primódios foliares diferenciados (Fig. 7). Os primórdios, logo que saem da semente, ainda envolvidos por tecido cotiledonar, desenvolvem-se perpendicularmente ao eixo do cotilédone (Fig. 3-4). A plúmula ainda envolvida pela lígula (Fig. 3), tem o primeiro e o segundo primórdio de formato tubular, que ficarão apenas no estádio de bainha 


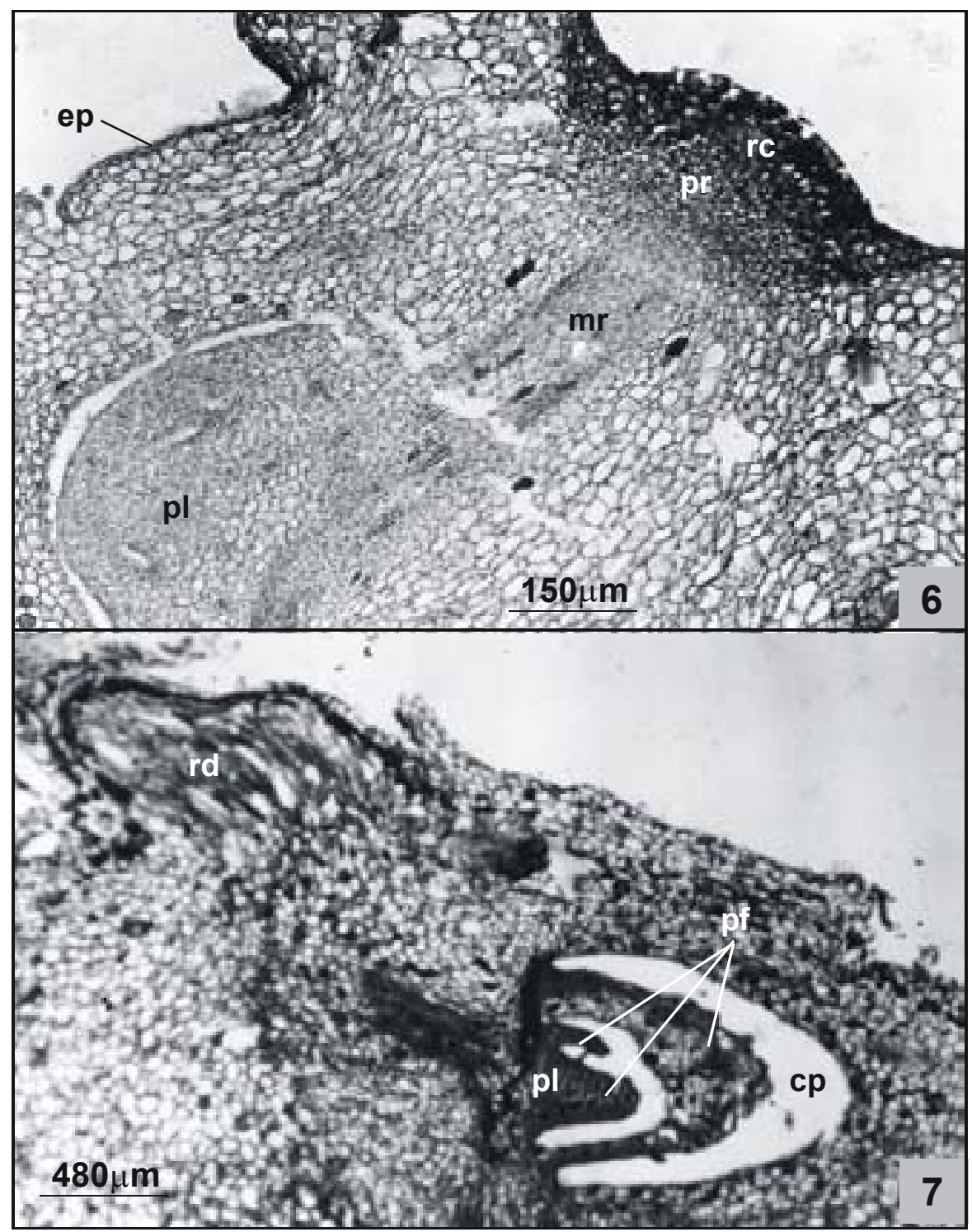

Figura 6-7. Embrião de Euterpe precatoria em secção longitudinal. cp, cavidade da plúmula; ep, epiderme; mr, meristema radicular; pf, primórdios foliares; pl, plúmula; pr, pólo radicular; rc, região da coifa; rd, raiz primária.

denominada neste trabalho, de bainha 1 e 2 . Neste estádio, o terceiro primórdio ainda é muito rudimentar e envolve um quarto primórdio que se inicia; ambos serão a primeira e segunda folha clorofilada, respectivamente (Fig. 10 e 11).

As bainhas são pontiagudas e rígidas, o que facilita a penetração no substrato e a saída através da fenda ligular. Esta é uma abertura oblíqua que aparece próximo à extremidade, em la- dos opostos de ambas as bainhas (Fig. 10). As fendas da primeira e da segunda bainha são os locais por onde saem a segunda bainha e a primeira folha clorofilada, respectivamente. Esta fenda oblíqua nas bainhas, também foi observada por Belin-Depoux \& Queiroz (1971) em Euterpe edulis.

Num estádio posterior, quando inicia a protrusão do eófilo ou primeira folha clorofilada 

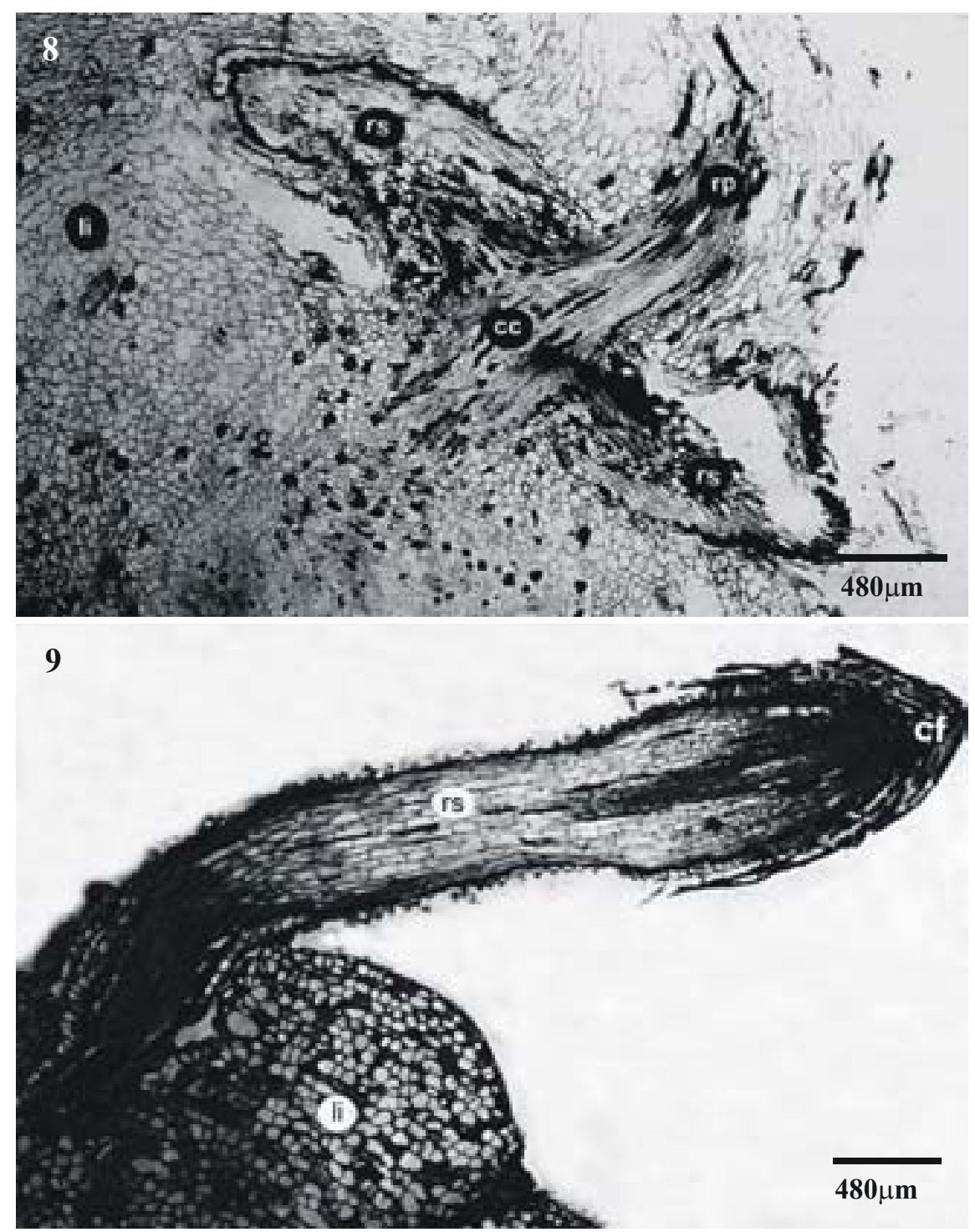

Figuras 8-9: Secção longitudinal do sistema radicular. 8: Região de formação das raízes secundárias. 9: Aspecto geral da raiz secundária. cc - cilindro central; $\mathrm{cf}$ - coifa; li - lígula; $\mathrm{rp}$ - raiz primária; rs - raiz primária; rs - raiz secundária.

(Fig. 5), as bainhas, em corte longitudinal, têm suas células organizadas em fileiras paralelas bem definidas, as mais próximas à epiderme são menores e as da epiderme são bastante achatadas e alongadas, de difícil visualização (Fig. 12). Em corte transversal, os feixes vasculares estão paralelos e distribuídos da seguinte maneira: os feixes de maior diâmetro são intercalados por um feixe de diâmetro mais reduzido (Fig. 13).
Neste estádio do desenvolvimento, a primeira folha clorofilada apresenta os folíolos individualizados, indicando sua forma pinada, sendo ainda formados por tecido meristemático e feixes vasculares já diferenciados; na sua base há dois primórdios foliares bastante rudimentares (Fig. 12 e 13). De acordo com Belin-Depoux \& Queiroz (1971), a separação dos folíolos em Euterpe edulis inicia-se antes do surgimento do pecíolo. 


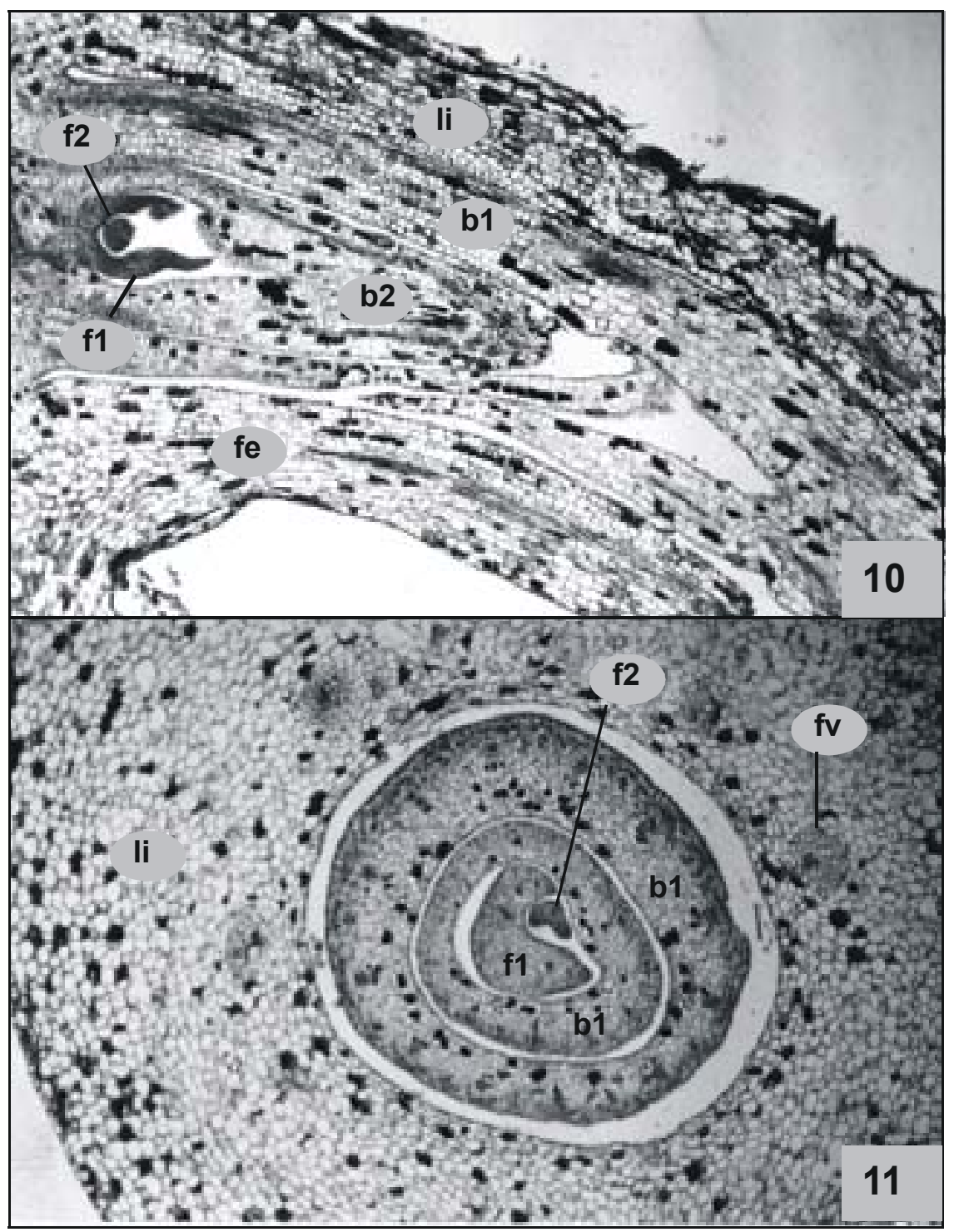

Figuras 10-11. Fase que precede a emergência dos primórdios de Euterpe precatoria. 10: secção longitudinal. 11. secção transversal. b1, primeira bainha; b2, segunda bainha; f1, primeira folha; f2, segunda folha; fe, fenda; fv, feixe vascular; li, lígula.

No pecíolo cotiledonar os feixes vasculares são freqüentes, comunicando o haustório à plântula. As células parenquimáticas são alongadas na direção do eixo longitudinal do embrião, com parede muito espessa e pontuada, o que confere rigidez ao pecíolo (Fig. 5 e 14). Este alongamento das células é interpretado por Corner (1966), Belin-Depoux \& Queiroz (1971) e Dassanayake \& Sicakadachchan
(1973), como responsável pela saída do eixo embrionário da semente.

À medida que o embrião se desenvolve, a região distal, o haustório, aumenta de tamanho, ocupando quase que totalmente o lugar do endosperma (Fig. 5). O haustório no início de seu desenvolvimento é percorrido longitudinalmente por feixes vasculares que, posteriormente, direcionam-se à periferia do mesmo em continuida- 


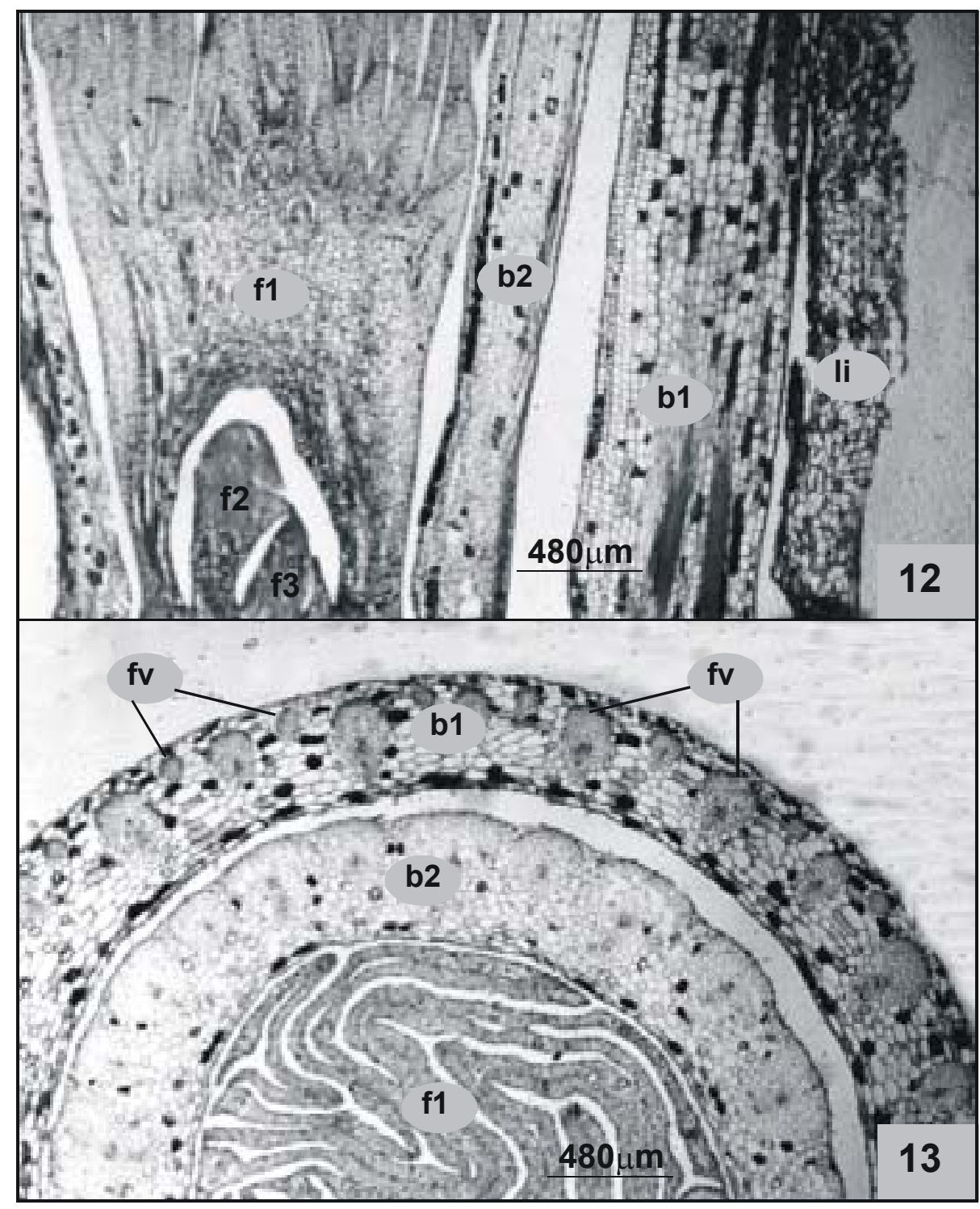

Figuras 12-13. Momento da emergência do eófilo de Euterpe precatoria. 12: secção longitudinal. 13: secção transversal. b1, primeira bainha; b2, segunda bainha; ep, epiderme; f1, primeira folha; $\mathbf{2}$, segunda folha; $\mathbf{f}$, terceira folha; fv, feixe vascular; li, lígula

de com o eixo da plântula (Fig. 14 e 15). DeMason (1988) observou em Washigtonia filifera, que a primeira evidência de diferenciação dos feixes vasculares no haustório, ocorre quando a lígula se forma. Ainda estudando os mecanismos de crescimento do haustório, ele observou que ocorre devido aos seguintes fatores: divisão celular nas camadas mais externas; aumen- to das células do parênquima interno e aparecimento de muitos espaços intercelulares. No final, o haustório é constituído de $63 \%$ de espaço intercelular e $37 \%$ de volume celular.

No haustório de Euterpe precatoria duas regiões são distintas: a região periférica e a região interna. Na região periférica as células são menores e justapostas, enquanto que na região in- 


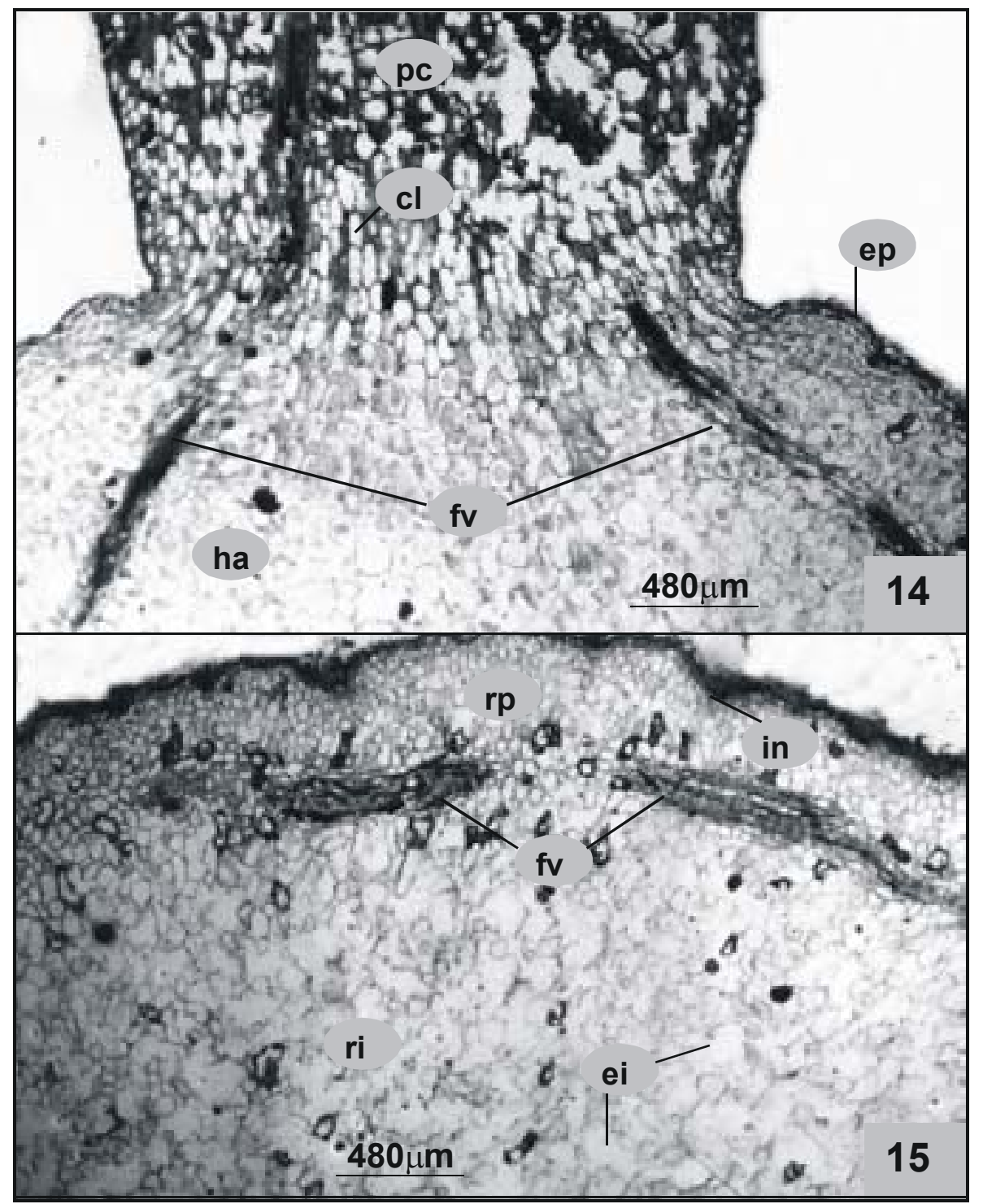

Figuras 14-15. Momento da emergência do eófilo de Euterpe precatoria em secção longitudinal. 14: região de transição entre pecíolo cotiledonar e haustório. 15: detalhe do haustório. cl, células longas; ei, espaço intercelular; ep, epiderme; fv, feixes vasculares; ha, haustório; in, invaginações; pc, pecíolo cotiledonar; ri, região interna; rp, região periférica.

terna, as células são maiores e com grandes espaços intercelulares. Os feixes vasculares estão distribuídos em um anel contínuo separando as duas regiões. Na sua superfície em contato com o endosperma, formam-se invaginações que retêm fragmentos de tecido endospermático (Fig. 15). Corner (1966) e Sugimura \& Murakami (1990) observaram estas invaginações do haus- tório de Cocos nucifera, as quais o primeiro autor denominou de papilas.

Nos últimos estádios de desenvolvimento do haustório (Fig. 5), o mesmo tem uma coloração branca e aspecto esponjoso que, quando pressionado, libera uma substância líquida. Os feixes vasculares são escassos e algumas vezes não são observados. De acordo com DeMason 
(1988), em Washingtonia filifera quando o eófilo se forma, os feixes vasculares não são mais visíveis no haustório.

\section{Referências bibliográficas}

Belin-Depoux, M. \& Queiroz, M. H. 1971. Contribution à l'étude ontogénique des palmiers. Quelques aspects de la germination de Euterpe edulis Mart. Revue Générale de Botanique (78): 339-371.

Belin, M. \& Queiroz, M. H. 1988. Contribuição ao estudo ontogenênico das palmeiras. Alguns aspectos da germinação de Euterpe edulis Mart. Pp. 211-213. In: Anais do I Encontro Nacional de Pesquisadores em Palmito. EMBRAPA-CNPF, Curitiba.

Calzavara, B. B. G. 1972. As possibilidades do açaizeiro no estuário amazônico. Boletim da Faculdade de Ciências Agrárias (5): 165-230.

Castro, A. 1992. O extrativismo do açaí no Amazonas. Relatório de Resultados do Projeto de Pesquisa: Extrativismo na Amazônia Central, viabilidade e desenvolvimento. Convênio INPACNPq/ORSTOM, Manaus.

Corner, E. J. H. 1966. The Natural History of Palm. Weidenfeld and Nicolson, London.

Dassanayake, M. D. \& Sivakadachchan, B. 1973. Germination and seedling of Borassus flabellifer L.
Ceylon Journal Science Biology 10(2): 5 .

DeMason, D. A. 1988. Seedling development in Washingtonia filifera (Arecaceae). Botanical Gazette 149(1): 45-56.

Henderson, A. 1995. The palms of the Amazon. University Press, Oxford.

Kanh, F. \& Granville, J. 1992. Palms in forest ecosystems of Amazonia. Ecological Studies, vol. 95, p. 226.

Kraus, J. E. \& Arduin, M. 1997. Manual básico de métodos em Morfologia Vegetal. EDUR, Rio de Janeiro.

Nogueira, O.L.; Carvalho, C.J.R.; Muller, C.H.; Galvão, E.U.P.; Silva, H.M.; Rodrigues, J.E.L.F.; Oliveira, M.S.P.; Carvalho, J.E.U.; Rocha Neto, O.G.; Nascimento, W.M.O. \& Calzavara, B.B.G. 1995. A cultura do açaí. Coleção plantar. EMBRAPA-SPI, Brasília-DF.

Pinheiro, C.U.B. 1986. Germinação de sementes de palmeiras: revisão bibliográfica. EMBRAPAUEPAE, Teresina.

Rees, A. R. 1960. Early development of the oil palm seedling. Principes 4(4): 148-150.

Sugimura, Y. \& Murakami, T. 1990. Structure and function of the haustorium in germinating coconut palm seed. JARQ. 24:1-14.

Tomlinson, P.B. 1990. The Structural Biology of Palms. Clarendon Press, Oxford. 
